\title{
A shallow geothermal experiment in a sandy aquifer monitored using electric resistivity tomography
}

\author{
Thomas Hermans ${ }^{1}$, Alexander Vandenbohede ${ }^{2}$, Luc Lebbe ${ }^{2}$, and Frédéric Nguyen ${ }^{3}$
}

\begin{abstract}
Groundwater resources are increasingly used around the world for geothermal exploitation systems. To monitor such systems and to estimate their governing parameters, we rely mainly on borehole observations of the temperature field at a few locations. Bulk electric resistivity variations can bring important information on temperature changes in aquifers. We have used surface electric resistivity tomography to monitor spatially temperature variations in a sandy aquifer during a thermal injection test. Heated water $\left(48^{\circ} \mathrm{C}\right)$ was injected for 70 hours at the rate of $871 / \mathrm{h}$ in a $10.5^{\circ} \mathrm{C}$ aquifer. Temperature changes derived from time-lapse electric images were in agreement with laboratory water electric conductivity-temperature measurements. In parallel, a coupled hydrogeologic saturated flow
\end{abstract}

and heat transport model was calibrated on geophysical data for the conceptual model, and on hydrogeologic and temperature data for the parameters. The resistivity images showed an upper flow of heated water along the well above the injection screens and led to a new conceptualization of the hydrogeologic source term. The comparison between the temperature models derived from resistivity images and from the simulations was satisfactory. Quantitatively, resistivity changes allowed estimating temperature changes within the aquifer, and qualitatively, the heated plume evolution was successfully monitored. This work demonstrates the ability of electric resistivity tomography to study heat and storage experiments in shallow aquifers. These results could potentially lead to a number of practical applications, such as the monitoring or the design of shallow geothermal systems.

\section{INTRODUCTION}

Groundwater plays a major part in the production of geothermal energy, which is increasingly growing worldwide. For instance, in 2010 , geothermal heat pumps accounted for $47.2 \%$ of thermal energy use and $68.3 \%$ of total installed capacity in the world (Lund, 2010). Geothermal energy resources therefore constitute an essential field of research and development in the diversification of energy resources to hinder global warming.

Very-low temperature systems $\left(<30^{\circ} \mathrm{C}\right)$ are much more easily accessible and involve lower implementation costs than deeper high temperature systems. Moreover, very-low temperature systems, such as shallow aquifers, are relatively abundant in alluvial or coastal plains where urban development concentrates. From 0 to less than 100 meters depth, groundwater has an average temperature ranging from $5^{\circ} \mathrm{C}$ to $30^{\circ} \mathrm{C}$ and may be used for cooling or heating (Allen and Milenic, 2003).

Exploitation of geothermal energy relies on either extraction (or storage) of groundwater (or heated water) through pumping (or injection) wells or on heat exchange between the geological medium and a fluid circulating in a closed and buried circuit (Lund et al., 2005). To design such systems, engineers must estimate the parameters governing heat transport processes, which are mainly heat capacity and thermal conductivity of fluid and solid (Busby et al., 2009). Engineers generally rely on standard calculation charts, which may not be representative of in situ conditions, such as the influence of the soil/rock, the well and the fluid, or on thermal response tests in wells, which deliver only well-centered information (similar to pumping tests). In this context, electric resistivity tomography (ERT) can bring relevant spatial and temporal

\footnotetext{
Manuscript received by the Editor 9 June 2011; revised manuscript received 8 September 2011; published online 13 February 2012.

${ }^{1}$ University of Liege, Department ArGEnCo, Applied Geophysics, Liege, Belgium and F.R.S.-FNRS, Aspirant, Brussels, Belgium. E-mail: thomas.hermans@ ulg.ac.be.

${ }^{2}$ Ghent University, Department of Geology and Soil Science, Research Unit Groundwater Modelling, Ghent, Belgium. E-mail: alexander.vandenbohede@ ugent.be; luc.lebbe@ugent.be.

${ }^{3}$ University of Liege, Department ArGEnCo, Applied Geophysics, Liege, Belgium. E-mail: f.nguyen@ulg.ac.be.

(c) 2012 Society of Exploration Geophysicists. All rights reserved.
} 
information through the correlation between temperature and bulk electric resistivity changes with a greater coverage than single wells for in situ studies.

Bulk electric resistivity of soil/rock samples decreases with temperature (e.g., Revil et al., 1998; Hayley et al., 2007). This correlation reflects the change in conductivity of water contained in the pores but also in the surface conductivity of grains. The first effect is related to changes in the fluid viscosity, whereas the second is due to changes in the surface ionic mobility. As a result, temperature corrections in time-lapse series may be necessary to correct electric resistivity tomography results to avoid misinterpretation when explaining resistivity changes (e.g., Hayley et al., 2007, 2010; Ma et al., 2011).

Geothermal experiments have been performed for several decades in hydrogeology. Buscheck et al. (1983), Molson et al. (1992), or Vandenbohede et al. (2009), for example, simulate thermal injection and recovery experiments and heat tracing (e.g., Anderson et al., 2005, for a review) tests have been used to study groundwater reservoirs.

A parallel can be done between temperature monitoring (Anderson, 2005) and salt tracer test (Ptak et al., 2004). Temperature and salt concentration both have an effect on fluid and surface electric conductivity (Revil et al., 1998). As shown recently by Singha et al. (2011), traditional chemically conservative tracers may not be electrically conservative due to phenomena like ion exchanges, mass transfers, or surface conductance. Temperature may also modify chemical processes by changing equilibrium constants or reaction kinetics. Both effects modify the density of the fluid, but in an opposite way. Saline tracers can be used to generate very high electrical resistivity contrasts (typically around 10 to 1 ), but an increase in salinity will increase water density and potentially lead the tracer to sink down the aquifer (e.g., Kemna et al., 2002). It is difficult to reach such a contrast with heat tracers, but an increase in temperature will decrease the density, which is favorable when monitoring from the surface because the injected tracer will not sink. An analogy exists concerning the flow and transport model for both types of tracer (e.g., Anderson, 2005; Langevin et al., 2010), but using thermal tracers enables the derivation of governing parameters for heat transport processes. The monitoring design with ERT will be similar for both cases, but the interpretation needs to use appropriate petrophysical relationships.

ERT has been applied to study heat reservoirs where hydrothermal fluids generate high resistivity contrasts due to their temperature often exceeding $150^{\circ} \mathrm{C}$. In those situations, ERT can detect the reservoir itself, map preferential flow paths, and is useful to characterize rock properties (e.g., Pérez-Flores and Gomez Trevino, 1997; Bruno et al., 2000; Garg et al., 2007; Arango-Galván et al., 2011). Recently, several studies were carried out to image volcano hydrothermal systems with very long resistivity cables, showing that ERT is a reliable tool to detect hydrothermal features (e.g., Revil et al., 2010, 2011). ERT has also been used to study seasonal changes in permafrost rock walls. A resistivity-temperature relationship was calibrated around and below the freezing point to give quantitative information on frozen rock temperatures (Krautblatter et al., 2010).

Time-lapse measurements were also used to monitor geothermal systems. Legaz et al. (2009) used ERT and self-potential measurements to image the effect of the variations in Inferno Crater Lake level in New Zealand. ERT highlighted a large decrease in resistivity as the water level in the lake decreased.

Ramirez et al. (1993) use cross-borehole time-lapse ERT to monitor a steam injection during a restoration process. Changes in resistivity were related to an increase in water and soil temperature, a displacement of pore water and changes in ionic content of this water.

LaBrecque et al. (1996b) monitored temperature changes in the context of Joule heating combined to vapor extraction during a remediation process with cross-boreholes time-lapse ERT. They compared their results with temperature measurements but did not proceed to a conversion of ERT results into temperature. They analyzed differences in conductivity cell by cell to remove the spatial variability influence which remains constant during the heating. After 7 days of heating, the mean temperature increased by $17^{\circ} \mathrm{C}$, they found mean temperatures in agreement with their expectations. After 14 days, the temperature reached $100^{\circ} \mathrm{C}$ and the change in conductivity was bigger than expected by temperature effects only. It was explained by a decrease in saturation. After 28 days of heating, conductivites were much below the background values showing an important loss of water produced by desaturation.

To our knowledge, few studies have used time-lapse surface ERT to estimate the characteristics of heat exchange and fluid transport during a geothermal tracer experiment at low temperature and small scale, typical of very-low enthalpy geothermal systems. Benderitter and Tabbagh (1982) carried out an experiment where injected heated water in a 4 to $7 \mathrm{~m}$ depth confined aquifer was monitored with DC resistivity measurements. The electric current was injected into two electrodes and the potential was measured at a moving electrode with reference to a fixed one. The authors produced qualitative anomaly maps using percentage changes in potential. Due to limited computing power, these maps were interpreted using electric forward modeling of resistivity anomalies calculated for simple geometric subsurface models determined according to the injected volume. The existence of an electric anomaly in bulk electric resistivity $(-33 \%)$ resulting from injection of heated water $\left(40^{\circ} \mathrm{C}\right)$ was clearly demonstrated.

In this paper, we examine the potential of ERT to image an injection and storage experiment using heated water, and its contribution in calibrating coupled flow and heat transport models. The heated plume evolution was successfully imaged by ERT as it was injected in one well. Combined with temperature well logs, ERT images contributed to detect leakage in the injection well and to calibrate the source term in the thermohydrogeologic model. In addition, ERT-derived temperatures in the aquifer seem in accordance with the latter model.

The paper is organized as follows. First the study site is presented. Then, the methodology of the experiment is described: the injection procedure, petrophysical relationships, the thermohydrogeologic model, error assessment, and the inversion method are presented. The results section describes the background study of the site and the comparison to borehole data to validate ERT images. Results of time-lapse data collected after injection are also presented and are compared to thermohydrogeologic modeling results.

\section{FIELD SITE}

The field experiments took place on the campus De Sterre of Ghent University, Belgium, from 8 to 12 February 2010 (Figure 1). Figure 2 shows a schematic cross section of the site with lithological 
characteristics and the position of the water level, together with the well description. The upper layer lies from 0 to $-2 \mathrm{~m}$ and corresponds to unsaturated fine sands. From $-2 \mathrm{~m}$ down to $-4.4 \mathrm{~m}$, the same sands are found at saturation. These sands constitute homogeneous Quaternary deposits, as evidenced by nearby boreholes (W02 and W03 on Figure 1). Below -4.4 m, a clay layer of Tertiary age is found, forming a low permeability layer. The injecting well was drilled down to $-4.4 \mathrm{~m}$, it is made of a PVC casing with a screen of $90 \mathrm{~cm}$ at the bottom of the Quaternary layer. Calibrated sands were poured around the well along the screen, and bentonite cement was used to fill the upper part of the drilling hole as a hydraulic seal. The water table lies at $-2 \mathrm{~m}$ and is nearly flat on the site; a gradient of 0.005 toward the south-southwest was derived from three wells (W01, W02, and W03 on Figure 1). The temperature in the aquifer was $10.5^{\circ} \mathrm{C}$.

\section{METHODS}

\section{Heating and injection of water}

A slug test was performed in the injection well to estimate possible injection rates. A volume of 101 was injected and the evolution of the hydraulic head was followed with a pressure transducer. For a water temperature of $10.5^{\circ} \mathrm{C}$, a maximum rate of $70 \mathrm{l} / \mathrm{h}$ was estimated. However, for water at $48^{\circ} \mathrm{C}$, the decrease in viscosity enabled an injection rate of $87 \mathrm{l} / \mathrm{h}$.

For practical reasons, it was not possible to heat the formation water directly. This would have required two new pumping wells and would have led to logistics problems: control of pumping rates during all the experiment and storage of pumped formation water in containers outside of the building in cold air conditions before heating. Access to the unconfined aquifer was only possible in the injection well. Other wells intersecting the unconfined aquifer were located on the other side of the road (Figure 1). The use of resistance to heat the water through Joule dissipation (LaBrecque et al., 1996b) was not considered because it would only lead to conduction and no convection.

Tap water was thus used for the injection. Its temperature fluctuated between $9^{\circ} \mathrm{C}$ and $14^{\circ} \mathrm{C}$. After passing through a heating system consisting of two electric boilers having a capacity of 2001 and a power of $2200 \mathrm{~W}$, water temperatures varied between $45^{\circ} \mathrm{C}$ and $49^{\circ} \mathrm{C}$, with an average of $48^{\circ} \mathrm{C}$. Injection of heated water started at 9 February and lasted for 70 hours.

\section{Petrophysical relationships}

In this section, we will describe the relationship between temperature and water electric conductivity as well as the one between water electric conductivity and bulk electric conductivity.

A linear dependence between electric conductivity and temperature of soil/rock can be assumed when limited temperature intervals are considered (a few tens of degrees). Equation 1 expresses the linear relation around $25^{\circ} \mathrm{C}$ (Hayley et al., 2007):

$$
\frac{\sigma_{T}}{\sigma_{25}}=m(T-25)+1,
$$

where $\sigma_{T}$ is the electric conductivity of soil/rock at temperature $T$ (in ${ }^{\circ} \mathrm{C}$ ), $m$ is the fractional change in electric conductivity per degree Celsius. The value of $m$ can be experimentally determined and varies according to the type of fluid and sediments. A value between $0.018^{\circ} \mathrm{C}^{-1}$ and $0.025^{\circ} \mathrm{C}^{-1}$ is often found for $m$ (Hayley et al., 2007). Water and surfaces conductivity effects may be separated and expressed by similar equations with different fractional changes, $m^{f}$ and $m^{s}$, respectively. Revil et al. (1998) found $m^{f}$ equal to $0.023^{\circ} \mathrm{C}^{-1}$ and $m^{s}$ around $0.04^{\circ} \mathrm{C}^{-1}$ for surface conductivity on the temperature range $25^{\circ} \mathrm{C}-200^{\circ} \mathrm{C}$. The ratio of surface conductivity to the fluid conductivity increases with temperature and equation 1 does not apply for bulk conductivity.

Figure 1. The study area is located on the campus De Sterre of Ghent University; W01 gives the position of the injection well, W02 and W03 the position of two wells used to described the water level. The black line shows the position of ERT profile next to the geological institute.

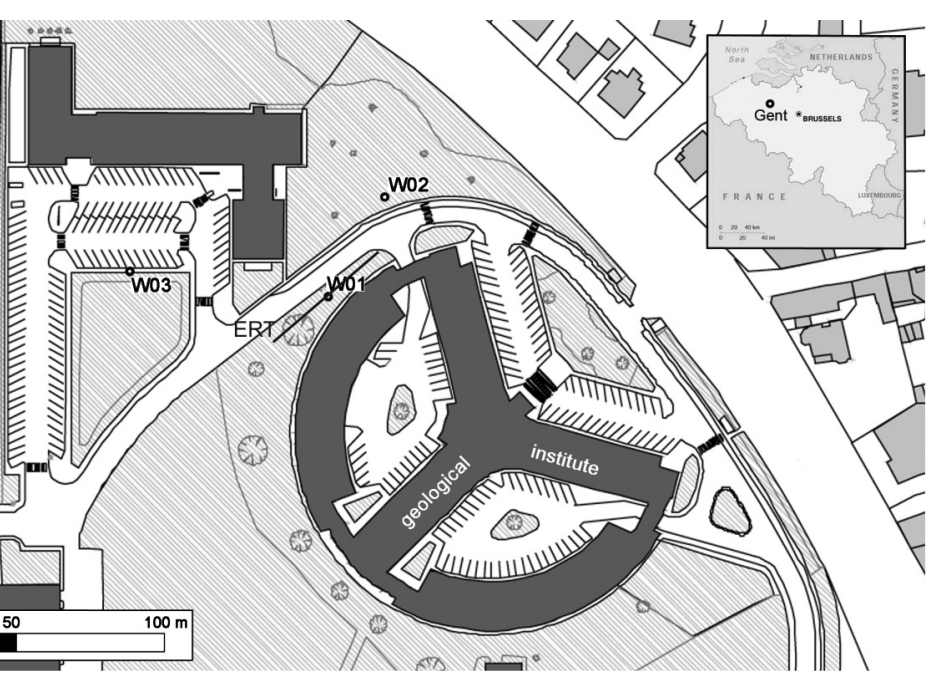


Hayley et al. (2007) apply the same model as Revil et al. (1998) on the temperature range $0^{\circ} \mathrm{C}-25^{\circ} \mathrm{C}$ and found $\mathrm{m}^{s}$ around $0.018^{\circ} \mathrm{C}^{-1}$ and $m^{f}$ equal to 0.0187 (Hayashi, 2004). These values are similar, leading globally to linear temperature dependence for the bulk electric resistivity.

Archie's law (equation 2) describes the link between the formation factor $F$ and the porosity $\phi$ through the cementation exponent $m$ (Archie, 1942):

$$
\frac{1}{F}=\phi^{m}
$$

The formation factor is used to link the bulk and fluid electric conductivity (equation 3) when surface conductivity can be neglected:

$$
\sigma_{b}=\frac{\sigma_{f}}{F}
$$

where $\sigma_{b}$ is the bulk electric conductivity of the soil/rock in $\mathrm{S} / \mathrm{m}$ and $\sigma_{f}$ is the electric conductivity of the fluid in $\mathrm{S} / \mathrm{m}$. Equation 3 does not involve surface conductivity. When the matrix conductivity is nonnegligible, in shaly and clayey sediments for example, additional terms are needed to take into account the surface conductivity of the solid. Equation 4 generalizes equation 3 to include the surface conductivity $\sigma_{s}$ :

$$
\sigma_{b}=\frac{\sigma_{f}}{F}+\sigma_{s} .
$$

Several authors (e.g., Waxman and Smits, 1968; Revil et al. 1998) give more complex equations to take into account the surface conductivity, using, for example, the cation exchange capacity.

In saturated sediments, equation 3 shows that the bulk electric conductivity is directly proportional to the fluid electric conductivity if we neglect the surface conductivity. In our study, the experiment took place in sandy sediments free of clays from the surface down to $-4.4 \mathrm{~m}$. Several authors (e.g., Revil et al., 1999; Revil and Linde, 2006; Bolève et al., 2007; Leroy et al., 2008) showed that silica grains have a surface conductivity, which cannot be neglected if the water is fresh enough (e.g., Jardani et al.,

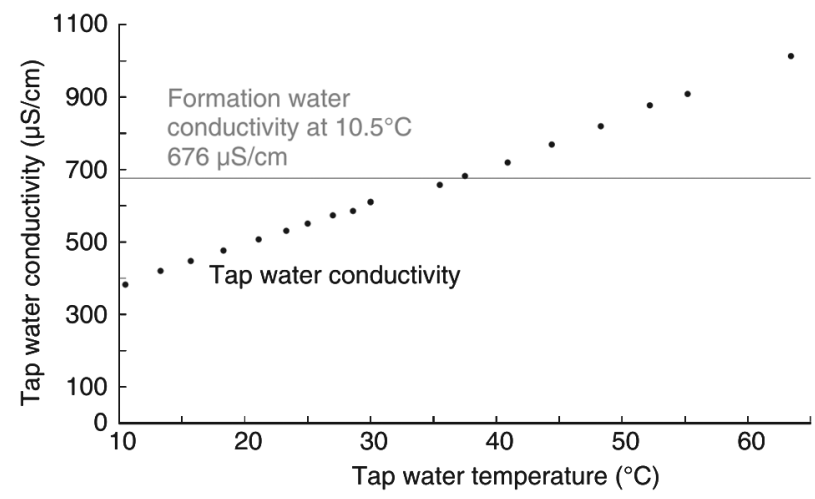

Figure 3. Electrical conductivity of the injected water increases linearly with temperature (points) according to our laboratory measurements, the fractional change per degree Celcius is about $2.1 \%$. The formation water at temperature of the aquifer (i.e., $10.5^{\circ} \mathrm{C}$, line) is more conductive than the injected water.
2009). According to Revil and Linde (2006), the surface electric conductivity increases when the diameter of the particles decreases:

$$
\sigma_{s}=\frac{6 \Sigma_{s}}{d_{0}}
$$

where $\Sigma_{s}$ is the specific surface conductivity in siemens and $d_{0}$ is the mean particle diameter in meters. If we assume the specific surface conductivity given by Bolève et al. (2007), $4.0 \times 10^{-9} \mathrm{~S}$ and a mean particle size diameter for the fine sands of $200 \mu \mathrm{m}$, we found a surface conductivity of $1.2 \times 10^{-4} \mathrm{~S} / \mathrm{m}$, which is three orders of magnitude below the water electric conductivity on the site, i.e., around $0.1 \mathrm{~S} / \mathrm{m}$. The role of the sediment surface electric conductivity was thus neglected.

In the clays of Tertiary age, equation 4 should be used to take into account the change in surface conductivity. Interpretation in terms of temperature was not considered in the clays because the surface conductivity effect cannot be neglected. Clay acts as an impermeable barrier avoiding convection processes, but conduction is still possible, leading to an increase in temperature of the clay.

In the unsaturated zone, Archie's law (equation 3) can be extended to account for water saturation $\mathrm{S}_{w}$

$$
\sigma_{b}=\frac{\sigma_{f}}{F} \mathrm{~S}_{w}^{n}
$$

where $n$ is an empirical exponent close to two. In consequence, electric conductivity changes in the unsaturated zone may be related to either saturation or temperature changes.

In the $10^{\circ} \mathrm{C}-50^{\circ} \mathrm{C}$ temperature interval considered for this experiment, a linear relationship can describe the link between temperature and water electric conductivity (Figure 3 ). Applying equation 1 for water electric conductivity, we obtain a fractional change in conductivity $m^{f}$ equal to 0.02125 per degree Celsius. This value is between the values obtained by Hayashi (2004) in the interval $0^{\circ} \mathrm{C}-25^{\circ} \mathrm{C}\left(m^{f}=0.0187\right)$ and by Revil et al. (1998) on the interval $25^{\circ} \mathrm{C}-200^{\circ} \mathrm{C}\left(m^{f}=0.023\right)$.

At $10.5^{\circ} \mathrm{C}$, tap water, which is used for injection, electric conductivity is $374 \mu \mathrm{S} / \mathrm{cm}$ whereas formation water conductivity is $676 \mu \mathrm{S} / \mathrm{cm}$ (Figure 3 ). At $48^{\circ} \mathrm{C}$, the average injection temperature, tap water electric conductivity reaches $818 \mu \mathrm{S} / \mathrm{cm}$. If both waters had the same conductivity, the increase in temperature would have led to an increase in water electric conductivity, and thus, in bulk electric conductivity, according to equation 3 , of $120 \%$. However, the increase in temperature from $10.5^{\circ} \mathrm{C}$ to $36^{\circ} \mathrm{C}$ first balances this difference of $302 \mu \mathrm{S} / \mathrm{cm}$ in electric conductivity instead of producing an electric conductivity anomaly, which appears only above $676 \mu \mathrm{S} / \mathrm{cm}$. Only the increase from 36 to $48^{\circ} \mathrm{C}$ contributes to produce an electric anomaly in the sand layer. In consequence, the maximum increase in bulk electric conductivity is equal to $21 \%$, the corresponding decrease in bulk electric resistivity is $17 \%$.

To interpret ERT time-lapse series in terms of temperature variations in the aquifer, we used the ratio of equation 3 between the time-lapse series and a background reference model, assuming that the formation factor is independent of the bulk conductivity. With equation 1, we derive the expected temperature from ERT measurements.

To take into account the difference in conductivity between formation and tap water, the injection was simulated with the calibrated hydrogeologic model (see below, "Heat and flow 
transport model"). We started from an aquifer filled with formation water and then simulated the injection during 70 hours of a solution whose conductivity was equal to the one of tap water, at a rate of $87 \mathrm{l} / \mathrm{h}$. The dispersivity was set at $0.2 \mathrm{~m}$, it was chosen according to results in similar Quaternary deposits (Vandenbohede and Lebbe, 2002; Vandenbohede et al., 2011). The transition between water electric conductivity in $\mathrm{S} / \mathrm{m}$ and concentration $C$ in $\mathrm{mg} / \mathrm{L}$, was made using Keller and Frischknecht (1966): $\sigma_{f} \approx \frac{C}{5000}$. Then, a temperature correction was applied according to the simulated conductivity of the water at the end of the injection. If the conductivity was equal to the conductivity of tap water, no correction was applied, and we can directly apply equation 1 to derive the temperature. If the conductivity was equal to the one of formation water, a correction of $-25.5^{\circ} \mathrm{C}$ was applied. This takes into account the fact that formation water has the same electric conductivity as tap water when its temperature is $25.5^{\circ} \mathrm{C}$ lower. Doing so, we assume that the fractional change in electric conductivity per degree Celsius $m$ (equation 1) is the same for the formation water. Between, these two conductivity limits, a linear variation was used to calculate the temperature correction, i.e., if the conductivity was equal to the mean between tap and formation water, a correction of $-12.25^{\circ} \mathrm{C}$ was applied.

\section{Heat and flow transport model}

Parameters responsible for heat transport in the aquifer are of special interest when studying geothermal systems. We carried out thermohydrogeologic modeling to identify those parameters and to assess their reliability. Temperature logs were taken before and after the test, as well as during the storage phase, i.e., after the end of injection. A complete description of this modeling can be found in Vandenbohede et al. (2011).

To simulate heat transport, the US Geological Survey computer program SEAWAT version 4 (Langevin et al., 2007) was used. This is a finite-difference solver, coupling MODFLOW-2000 (Harbaugh et al., 2000) with MT3DMS (Zheng and Wang, 1999). SEAWAT is capable of simulating heat transport taking into account density and viscosity changes.

We simulated the test with a 3D model constituted of 80 rows and 80 columns of $0.25 \mathrm{~m}$ each $(20$ by $20 \mathrm{~m}$ ) and 23 layers. The first eight layers are $0.3 \mathrm{~m}$ thick and represent Quaternary deposits, and the top of the model corresponds to the water table. The remaining layers represent clay deposits. The thicknesses are $0.3 \mathrm{~m}$ thick for layers 9 to $13,0.4 \mathrm{~m}$ for layers 14 and $15,0.5 \mathrm{~m}$ for layers 16 and $17,0.6 \mathrm{~m}$ for layers 18 and $19,0.7 \mathrm{~m}$ for layers 20 and $21,0.8 \mathrm{~m}$ for layer 22 and $0.9 \mathrm{~m}$ for layer 23. The geology building (Figure 1) is represented by the first 30 columns of the upper four layers, which are inactive. Western and eastern boundary are constant head boundaries representing the hydraulic gradient of $5 \times 10^{-3}$.

Constant temperature boundary conditions are applied in the first layer and in cells bordering the inactive cells representing the building. This temperature depends on air temperature and temperature of the groundwater recharge, which are subject to seasonal changes. We approximated this variation with a sinusoidal function calibrated, thanks to temperature measurements in W01 and W02 as done by Suzuki (1960) for instance. The influence of the building was taken into account by increasing the mean temperature of the aquifer next to it. With this seasonal model, we simulated the initial conditions for the heat injection test; details can be found in Vandenbohede et al. (2011).

A horizontal hydraulic conductivity of $0.5 \mathrm{~m} / \mathrm{d}$ was derived from slug tests performed in the well (Vandenbohede et al., 2011). The slug test was interpreted using guidelines given by Butler (1998) and interpreted with the KGS model (Hyder et al., 1994). For Tertiary deposits, we estimated a horizontal hydraulic conductivity of $0.1 \mathrm{~m} / \mathrm{d}$ from previous studies (Lebbe et al., 1992). Vertical conductivity was taken ten times smaller for both cases and we estimated an effective porosity of 0.35 , which is a typical value for sediments. These values are based on our knowledge of the lithology and results from previous experiments in similar Quaternay sediments (Vandenbohede and Lebbe., 2002, 2003, 2006). The groundwater recharge was estimated at $150 \mathrm{~mm} /$ year. Thermal properties of the medium are summed up in Table 1 .

The injection phase, the phase of interest for comparison with geophysical data, is simulated with one stress period of $70 \mathrm{~h}$ (2.92 days) subdivided in 300 time steps. The storage phase is simulated with 45 stress periods of one day subdivided in 10 time steps.

The model was calibrated by trial and error.

\section{Electric resistivity measurements}

We used an ABEM $^{\circledR}$ SAS 1000 Terrameter (single channel) with 64 take-outs and stainless steel electrodes with copper wire connectors. Dipole-dipole arrays generally lead to better results in terms of imaging but have a lower signal-to-noise ratio $(\mathrm{S} / \mathrm{N})$ (Dahlin and Zhou, 2004). On the field site, the level of noise was quite high. We attribute the origin of the ambient noise to the urban nature of the area (Figure 1). As a second choice, we used a Wenner-Schlumberger array with the $n$ factor lower than or equal to six and an unlimited $a$ factor with an electrode spacing of $0.75 \mathrm{~m}$. This array type has a higher $\mathrm{S} / \mathrm{N}$ than the dipole-dipole array. The average repeatability error was below $0.1 \%$. The array used to collect the data had 62 electrodes and 823 measurements points.

The ERT profile was centered on well W01, located at the abscissa $23.5 \mathrm{~m}$ on the profile, and parallel to the geological institute building (Figure 1). The total length was equal to $45.75 \mathrm{~m}$.

Table 1. Model parameters used in the SEAWAT model (Langevin et al., 2010; Vandenbohede et al., 2011).

Reference temperature

Fluid density - temperature relation

Reference viscosity

Porosity

Solid matrix density

Specific heat of the fluid

Specific heat of the solid

Distribution coefficient for temperature

Thermal conductivity of fluid

Thermal conductivity of solid

Bulk thermal conductivity

Bulk thermal diffusivity

$$
\begin{aligned}
& T_{\mathrm{o}}=10^{\circ} \mathrm{C} \\
& \partial \rho / \partial T=-0.375 \mathrm{~kg} /\left({ }^{\circ} \mathrm{Cm}^{3}\right) \\
& \mu_{\mathrm{o}}=0.001 \mathrm{~kg} /(\mathrm{ms}) \\
& \theta=0.35 \\
& \rho_{s}=2640 \mathrm{~kg} / \mathrm{m}^{3} \\
& \mathrm{c}_{F}=4183 \mathrm{~J} /\left(\mathrm{kg}^{\circ} \mathrm{C}\right) \\
& \mathrm{c}_{S}=710 \mathrm{~J} /\left(\mathrm{kg}^{\circ} \mathrm{C}\right) \\
& \mathrm{K}_{\mathrm{DT}}=1.6910^{-4} \mathrm{~m}^{3} / \mathrm{kg} \\
& \lambda_{F}=0.58 \mathrm{~W} /\left(\mathrm{m}^{\circ} \mathrm{C}\right) \\
& \lambda_{\mathrm{S}}=3 \mathrm{~W} /\left(\mathrm{m}^{\circ} \mathrm{C}\right) \\
& \lambda_{\mathrm{b}}=2.153 \mathrm{~W} /\left(\mathrm{m}^{\circ} \mathrm{C}\right) \\
& \mathrm{D}_{T}=0.127 \mathrm{~m}^{2} / \mathrm{d}
\end{aligned}
$$


Due to time and logistic constraints, it was not possible to carry out a 3D ERT study. We thus limited the test to this single 2D profile. Because, in this work, we were mainly interested in time-lapse data, the effect of the building on the electric measurements was supposed to be constant in time. This effect should therefore cancel when working in relative terms (LaBrecque et al., 2000; Kemna et al., 2002). In addition, Bowling et al. (2007) explain that the effect of a quarry cliff of infinite resitivity was only perceived within $5 \mathrm{~m}$ of an electric tomography profile (48 electrodes with a spacing of $2 \mathrm{~m}$ ). However, the targeted plume of heated water is $3 \mathrm{D}$ and some distortions could occur using a $2 \mathrm{D}$ survey leading to errors in the estimated magnitude of the anomaly (e.g., Bentley and Gharibi, 2004). In our case, the plume is expected to be symmetric, reducing the artifacts compared to a fully $3 \mathrm{D}$ heterogeneous medium.

The estimation of the data quality for ERT (noise level) is very important because the inverse electric problem is nonlinear (see section, Inversion procedure) and can lead to large amplifications of data noise in the electric image. An overestimation of the level of noise can lead to a smoothed final image. In contrast, when the noise level is underestimated, the inversion algorithm will generate rough and irregular structures to reproduce noisy data (LaBrecque et al., 1996a).

We used reciprocal measurements (Parasnis, 1988) to assess the error level in the data (LaBrecque et al., 1996a). Reciprocal measurements are obtained by swapping current and potential dipoles from normal measurements. To minimize acquisition time for the reciprocal measurements, 200 points were sampled out of the 823 with both normal and reciprocal measurements randomly chosen for each pseudodepth. Obviously, we kept all of the 823 normal measurements to invert our data sets.

Slater et al. (2000) propose a general procedure to assess the level of noise in a data set containing normal and reciprocal measurements. The reciprocal error $e_{N / R}(\mathrm{ohm})$ is defined as

$$
e_{N / R}=R_{N}-R_{R}
$$

where $R_{N}$ and $R_{R}$ are the normal and reciprocal resistance (ohm). The model proposes a linear variation of this error according to the mean resistance $R$ (ohm)

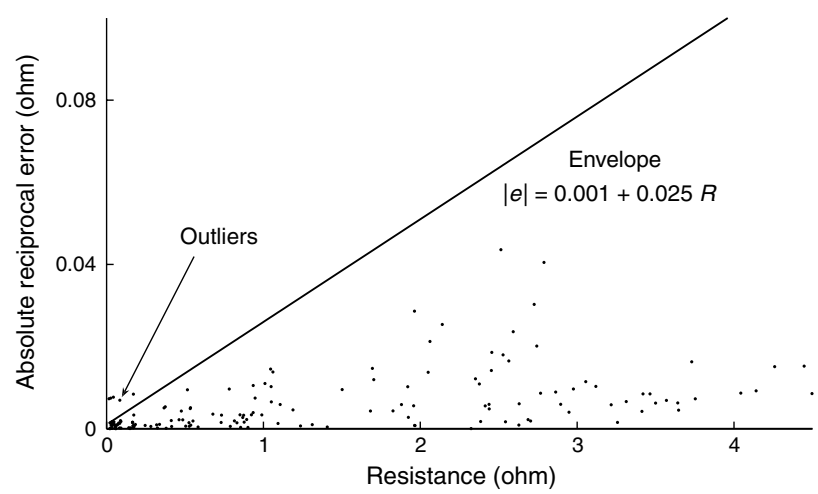

Figure 4. Reciprocal measurements are used to assess the error level (Slater et al., 2000). A linear model of the error is used to describe the envelope curve of the absolute reciprocal error according to the mean resistance. A minimum error of $0.001 \mathrm{ohm}$ and a relative error of $2.5 \%$ are found.

$$
\left|e_{N / R}\right|=a+b R
$$

where $a$ represents the minimum absolute error (ohm) and $b$ defines the relative increase of the error with the resistance. These parameters are determined by the envelope that contains all the points after removal of outliers. This is illustrated on Figure 4 for the 200 sample points. Obvious outliers were removed. The best fit for the envelope was found with a minimum absolute value of $0.001 \mathrm{Ohm}$ and a relative error of $2.5 \%$.

These parameters were used to assess the error level for each data point to weight the data during the inversion process and to fulfill the discrepancy principle (e.g., Aster et al., 2005) to stop the iterative inversion process. This error model was used for subsequent time frames to compare quantitatively the images.

\section{Inversion procedure}

Because the inverse electric problem is ill-posed, there is not a unique model that can explain these data. A common way to find a physically plausible solution is to regularize the problem with additional constraints (Tikhonov and Arsenin, 1977):

$$
\psi(\mathbf{m})=\psi_{d}(\mathbf{m})+\lambda \psi_{m}(\mathbf{m}) .
$$

Equation 9 expresses the objective function of the regularized problem where the first term of the right side expressed the data misfit and the second term, the misfit with an a priori model characteristic (roughness). The regularization parameter $\lambda$ quantifies the compromise between these two terms. The solution of the inverse problem is based on the minimization of the objective function (equation 9 through an iterative process (Kemna, 2000). Equation 9) can be expressed as

$$
\psi(\mathbf{m})=\left\|W_{d}(\mathbf{d}-f(\mathbf{m}))\right\|^{2}+\lambda\left\|W_{m} \mathbf{m}\right\|^{2}
$$

where $W_{d}$ is the data weighting matrix, based in our case on the reciprocal error, $f$ is the nonlinear operator mapping the log conductivities of the model $\mathbf{m}$ to the log impedance data set $\mathbf{d}$ and $W_{m}$ is the roughness matrix (deGroot-Hedlin and Constable, 1990). We refer to Kemna (2000) for more details on the implementation of the iterative scheme (choice of $\lambda$, etc.). The iteration process is stopped when the rms value of error-weighted data misfit reaches the value one for a maximum possible value of $\lambda$, i.e., the data are fitted within their error level.

For the background image, we added a structural constraint by modifying $W_{m}$ following the methodology described by Kaipio et al. (1999). At a point $x$ close to a defined discontinuity, the smoothness constraint is modified such that the penalty to a rapid change of the model is smaller toward the discontinuity than along it. We refer to Kaipio et al. (1999) for more details.

For the time-lapse series, we used the procedure described by LaBrecque and Yang (2000) and Kemna et al. (2002), referred to as difference inversion. The background model $\mathbf{m}_{0}$ serves as a reference for the time-lapse inversion of temporal changes in the data $\mathbf{d}-\mathbf{d}_{0}$, the latter being the background data. The objective function to minimize becomes (Kemna et al., 2002) 


$$
\begin{aligned}
\psi_{\text {diff }}(\mathbf{m})= & \left\|W_{d}\left[\mathbf{d}-\mathbf{d}_{0}+f\left(\mathbf{m}_{0}\right)-f(\mathbf{m})\right]\right\|^{2} \\
& +\lambda\left\|W_{m}\left(\mathbf{m}-\mathbf{m}_{0}\right)\right\|^{2}
\end{aligned}
$$

Assessing the quality of an ERT image and the reconstruction of electric resistivity is a major point when interpreting imaging results. Because the parameter resolution matrix of the inverse problem (Alumbaugh and Newman, 2000) is computationally expensive to calculate, other image appraisal tools may be used, such as the cumulative sensitivity matrix (Kemna, 2000; Nguyen et al., 2009), which was used in this study:

$$
S=J^{T} W_{d}^{T} W_{d} J
$$

\section{RESULTS}

\section{Background image}

Before the heated water injection started, a background image was collected in February 2010 to serve as a reference for subsequent time-lapse series.

Standard smoothness constraint regularization was first used to invert the data (equation 10). The error model of equation 8 was used to weight the data. It yielded a smooth model with gradual changes from high surface resistivity corresponding to the unsaturated sand to low-resistive clay (Figure 5a). The transitions between unsaturated and saturated zones or sand and clay are not clearly observable. To take into account available prior information and to better define the saturated sand, which is the zone of injection, additional structural constraints (Kaipio et al., 1999) deduced from borehole evidences were included to improve the solution. At $-2 \mathrm{~m}$ and $-4.5 \mathrm{~m}$, where we know that a horizontal limit exists, the horizontal/vertical anisotropy ratio in the smoothness constraint inversion was set at $1000: 1$, i.e., the smoothing effect of the inversions is 1000 lower vertically than horizontally. It permits reduction of the vertical smoothing effects at these locations and so to avoid smoothing effects between unsaturated and saturated zones and sands and
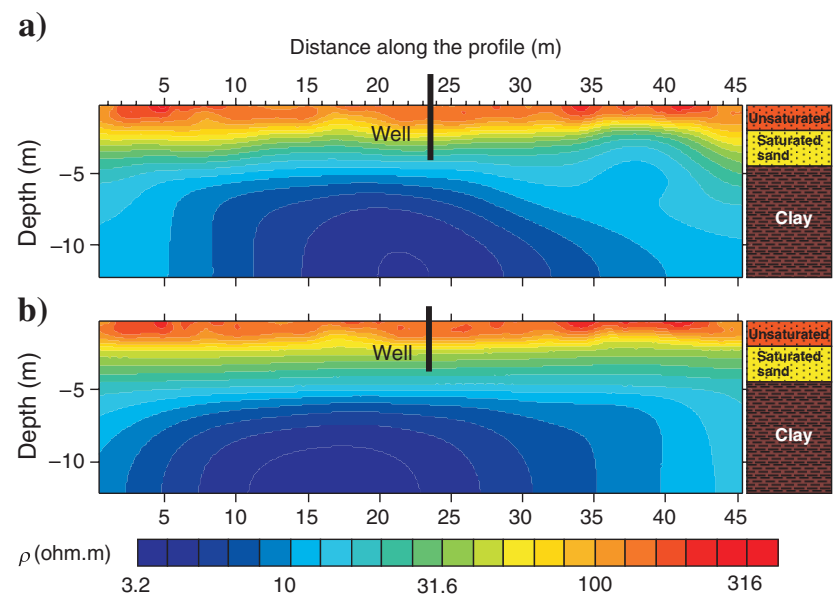

Figure 5. The correspondence between ERT and borehole data is improved when structural constraints are added (b) to the standard smoothness constraint (a). The saturated sands are better described, which is important because it constitutes the zone of injection. clays, respectively. It yields the background image (Figure 5b). The comparison between the two models (Tikhonov regularization and with structural constraints) shows that the layers boundaries are sharper.

The lithological/hydrological layering is clearly visible on the ERT image (Figure 5b). The first layer, corresponding to unsaturated sand in the upper $2 \mathrm{~m}$, displays resistivity values between 100 and $200 \mathrm{ohm}-\mathrm{m}$, decreasing from the surface to the bottom with increasing saturation (see equation 6). At abscissa 5, 35 and $40 \mathrm{~m}$, resistivity increases up to $300 \mathrm{ohm}-\mathrm{m}$; this is due to the presence of indured sands in the upper part of the sand layer. From $2 \mathrm{~m}$ below the surface down to $-4.4 \mathrm{~m}$, the sands are saturated; we thus observe a decrease in resistivity down to about $30 \mathrm{ohm}-\mathrm{m}$. At the depth of $4.4 \mathrm{~m}$, the resistivity values decrease again, with values below $10 \mathrm{ohm}-\mathrm{m}$, due to the presence of sandy clay.

\section{Time-lapse electric images}

Using the background resistivity model (Figure 5b) as a starting model and reference model (equation 11), resistance changes were inverted to reproduce resistivity models $24 \mathrm{~h}, 48 \mathrm{~h}$, and $72 \mathrm{~h}$ after the beginning of injection of heated water. We used the same noise level for all the data. The results are displayed in Figure 6 in terms of percentage change in bulk electric resistivity.

Because ERT is a nonlinear inverse problem, the injection of heated water and subsequent modification of the bulk electric resistivity distribution can modify the resolution and sensitivity pattern in time and space (Singha and Gorelick, 2006). In this case, a small increase in sensitivity is expected because the new distribution of bulk resistivity will display a zone of smaller resistivity in the center

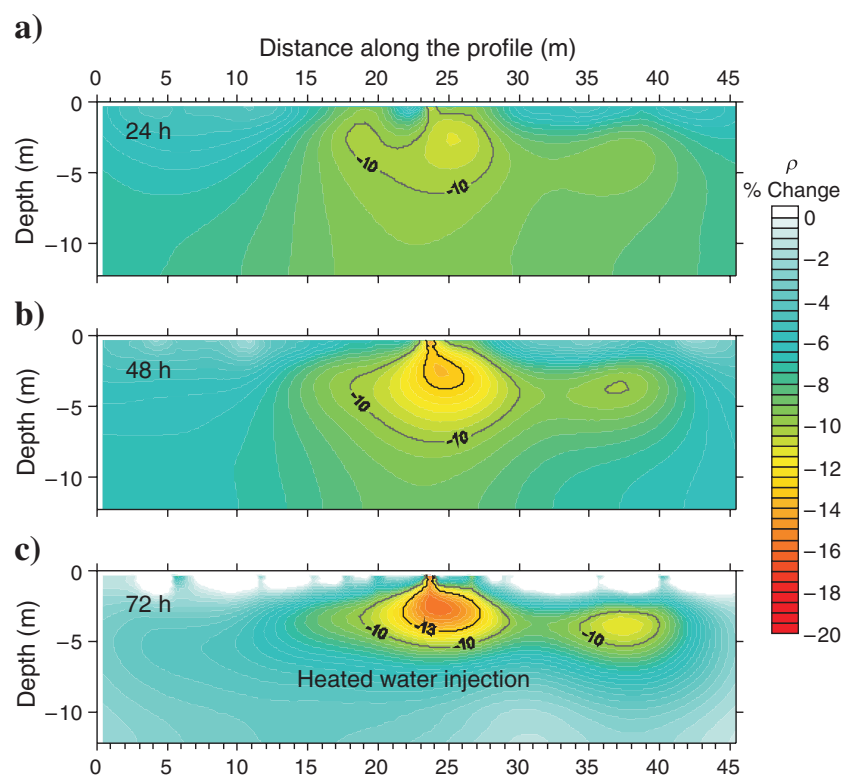

Figure 6. The plume of heated water is detected as an increasing negative anomaly (i.e., decrease in bulk electrical resistivity) in the time-lapse series after (a) $24 \mathrm{~h}$, (b) $48 \mathrm{~h}$, and (c) $72 \mathrm{~h}$. The minus $13 \%$ isoline, highlighted in black, illustrates the growing heated water anomaly. The minus $10 \%$ isoline is highlighted in gray; below this value changes are not directly interpretable due to the noise and changing weather conditions. 
of the profile due to the presence of the plume of heated water. This zone will focus current lines and improve the sensitivity.

To ensure that we avoid interpreting anomalies related to differential resolutions, we analyzed the cumulative sensitivity distribution (equation 12) for the different time frames. As an example, we compared the cumulative sensitivity before (background) and after $48 \mathrm{~h}$ of injection (Figure $7 \mathrm{a}$ and $7 \mathrm{~b}$, respectively). Changes in sensitivity are visible but are mostly limited to the deepest layers of the site, which are not concerned by the heated water injection, as shown by the comparison of the sensitivity logs at the position of the well (Figure 7c). For the zone concerned by this injection, from $-2 \mathrm{~m}$ to $-4.5 \mathrm{~m}$, sensitivity values remain within the same range and changes in resistivity from the background to the time-lapse series due to differential resolutions should be avoided.

The heated water plume is detected at the location of the injection well at different times as an increasing negative electric resistivity anomaly, in agreement with the petrophysical model presented above, as illustrated by the minus $13 \%$ change in bulk electric

a)

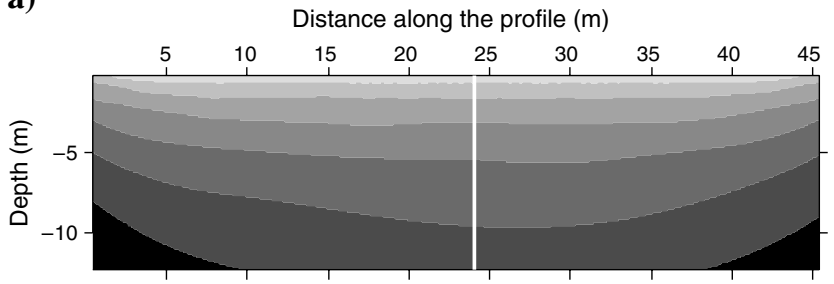

b)

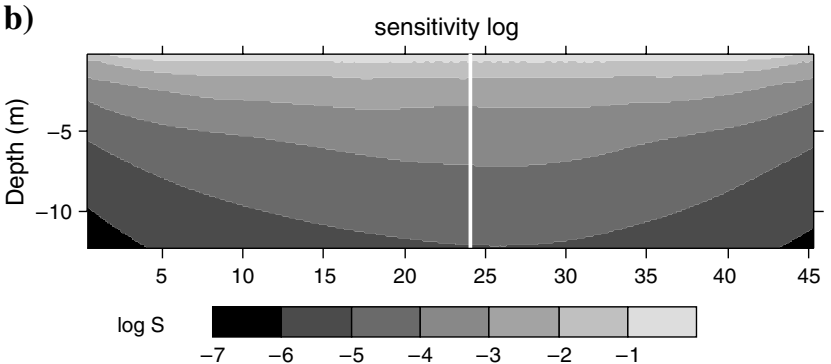

c)

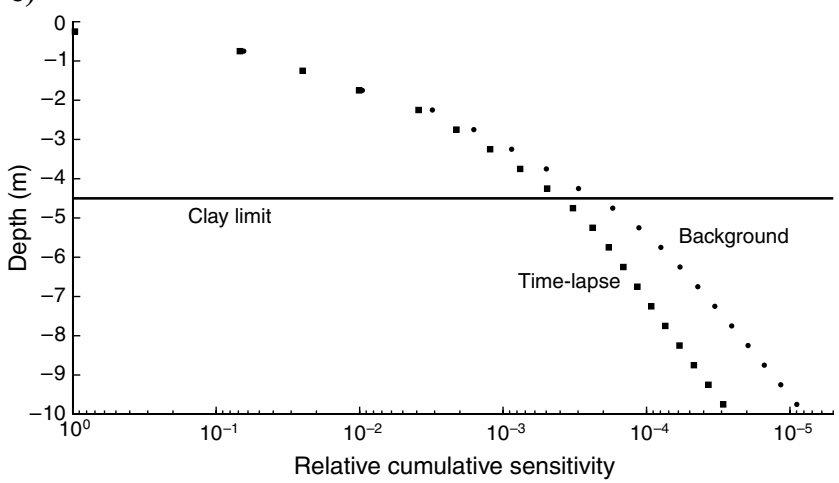

Figure 7. The cumulative sensitivity before the test (a) and during the test (b) remain similar in the zone of injection (between -2 and $-4.5 \mathrm{~m}$ ), artifacts due to different resolutions should be avoided. A $\log$ of sensitivity at the position of the well (c) enabled to appreciate quantitatively this similarity. The maximum difference in the zone of injection is found at the bottom of the sand where the sensitivity is $8 \times 10^{-3}$ for the background and $5 \times 10^{-3}$ after 48 hours. resistivity isoline on Figure 6. The maximum amplitude change is detected at the end of injection at the center of the plume (Figure 6c). As explained previously, the maximum decrease in resistivity is around $17 \%$, which is lower than expected because injection water is more resistive (less conductive) than formation water at the same temperature (Figure 3 ). If both waters would have had similar electric conductivity, the maximum decrease would have been around $54 \%$. Due to the smoothing effect of inversion, the plume is enlarged, the decrease in resistivity concerns a bigger volume than expected and the maximum decrease is likely underestimated. Three-dimensional effects can also reduce the maximum decrease in resistivity.

After $24 \mathrm{~h}$ (Figure 6a), a change of $-12 \%$ in bulk electric resistivity is detected at the well. At this time, the volume of heated water injected in the well was limited to $2.1 \mathrm{~m}^{3}$, yielding a small anomaly that ERT can barely image. After $48 \mathrm{~h}$ (Figure 6b), the anomaly is enlarged and the change in resistivity is higher $(-15 \%)$. Because the volume of heated water injected is doubled $\left(4.2 \mathrm{~m}^{3}\right)$, ERT managed to image the plume in more details. At the end of injection (Figure 6c), the decrease in resistivity reaches its maximum (17\%). The geophysical inversions show that the plume extension is limited in depth by the clay layer. This result is also in accordance with the hydrogeology of the site because this layer is considered as impermeable.

A decrease of electric resistivity is observed above the top of the screen in the aquifer, between -2 and $-3.5 \mathrm{~m}$, where the bentonite seal was placed. This variation corresponds to an increase in temperature, as shown by temperature logs (Figure 8) carried out after the injection phase (Vandenbohede et al., 2011). Such an important increase in temperature could not be explained only by heating due to thermal conduction from the PVC casing (thermal conductivity of $0.17 \mathrm{~W} / \mathrm{mC}^{\circ}$ ). This phenomenon can be explained if the bentonite seal used to prevent leakage of injection water was not properly set up, inducing injection of heated water to reach the upper part of the aquifer. Another hydraulic conductivity anisotropy ratio, with a greater vertical component, could have a similar effect. However, even a forward flow and transport simulation with a $1: 1$

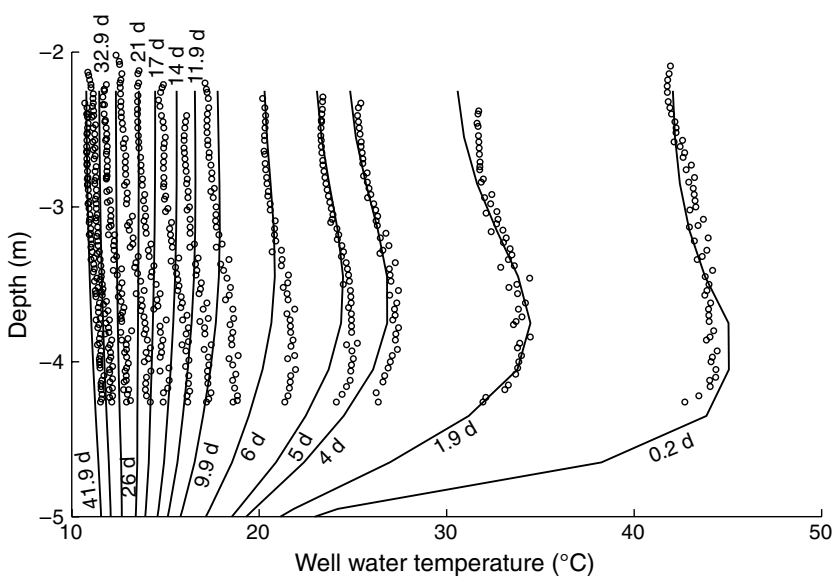

Figure 8. Temperature logs were taken after the injection in the injection well (W01) to control the temperature in the aquifer and to calibrate the thermohydrogeologic model. The misfit between observed (o) and calculated (solid line) temperature logs can be appreciated at different observation times (Vandenbohede et al, 2011). 
anisotropy ratio is not able to produce temperatures similar to the one observed with the logs. We thus favor the former hypothesis. In addition, we observe a bulk electric resistivity decrease in the unsaturated zone along the well, which could be caused by thermal conduction through the pipe.

On Figure $6 a$ and $6 b$, we see an almost systematic lowering of $5 \%$ in bulk electric resistivity across the entire image. In contrast, in Figure 6c, significant changes are limited to the zone of injection; elsewhere, variations are around $-3 \%$ at maximum. It is important to recall that all the inversions were run with the same level of noise, determined once with the reciprocal error. However, we think that the data quality (noise level), which was estimated only once after the injection, varied during the three days of injection (e.g., Miller et al., 2008). During the background, the weather was dry with air temperature above $0^{\circ} \mathrm{C}$. For the following two days, air temperature decreased below $0^{\circ} \mathrm{C}$ and snow fell. Surface conditions were thus completely different, which influenced the contact resistance at electrodes and therefore the noise level. This change might affect the overall quality of the image also at depth and might be reflected in the difference inversion through enhanced/reduced smoothing effect. As a result, the $-10 \%$ isoline seems larger after $48 \mathrm{~h}$ than after $72 \mathrm{~h}$. At the end of injection, temperature was again above zero and weather conditions were closer to that of the background.

To assess the minimal changes in temperature that could be detected by the electric survey, which depends mainly on the electric resistivity distribution, on the estimated $\mathrm{S} / \mathrm{N}$ and on the array design, we generated an ensemble of 100 geoelectric data sets by adding a $2.5 \%$ Gaussian random noise to the field data that was used to compute the background image (Figure 5). This ensemble was then inverted with the same inversion parameters (Kemna et al., 2007). We found that the distribution of each parameter follows a Gaussian distribution. The generated artificial electric resistivity changes are around $3 \%$ to $5 \%$, when considering changes between the average resistivity and the average resistivity minus one standard deviation. This would correspond to temperature variations of about $2^{\circ} \mathrm{C}$ to $3{ }^{\circ} \mathrm{C}$. As a result, we considered only changes two times greater than the noise-related changes $(10 \%$ in magnitude) as significant.

An anomaly is also present at $37 \mathrm{~m}$ from the beginning of the profile. At this position, a big tree was present. Barker and Moore (1998) show the influence of roots in the saturation of sands and this tree could explain why resistivities below $100 \mathrm{ohm}-\mathrm{m}$ are found less deep than elsewhere in the section (Figure 5). However, the cause of the $10 \%$ decrease in resistivity below the water table at this position is unclear.

\section{Comparison with thermohydrogeologic modeling}

In our initial modeling attempt, the injection rate was concentrated at the screen position. To account for the geophysical observations, which shows a temperature increase all along the well, it was necessary to spread the injection rate over the complete length of the well in the thermohydrogeologic model. Figure 8 shows, in support of the geophysical images, increased temperatures in the injection well, corresponding to downhole temperature profiles, above the screen during the storage phase, reflecting the failure of the bentonite to seal the annular space of the well. We assume that these temperatures are in equilibrium with water outside of the borehole. The results of the calibration process are presented in Table 1.

Resistivity values from ERT images were converted into temperature using equations 1 and 3 (called hereafter ERT-derived temperature). The main difficulty was to account for the difference in electric conductivity of formation water and tap water. To do so, we used the simulation from the calibrated model during the injection phase (see section Methods). It was then possible to compare our ERT results with the thermohydrogeologic model.

The comparison (Figure 9) shows that the horizontal and vertical positions of the plume after $72 \mathrm{~h}$ are correctly imaged, but the plume itself is enlarged. Before $72 \mathrm{~h}$, the volume of heated water is not big enough to be correctly imaged (not shown here). The enlargement of the plume can be easily explained by the smoothness constraint used to regularize the model differences in the inversion process and was also observed by Vanderborght et al. (2005) for a saline tracer.

The ERT-derived temperature image also shows changes near the surface in the unsaturated zone, between 0 and $-2 \mathrm{~m}$ depth. Here, saturation variations can also explain smaller resistivity values. The temperature values given in Figure $9 \mathrm{~b}$ in the unsaturated zone are not reliable because they assume similar saturations for the background and the time-lapse series.

Temperatures monitored with ERT are quite consistent with the thermohydrogeologic modeling after $72 \mathrm{~h}$. The maximum temperature deduced from ERT is $45^{\circ} \mathrm{C}$ which is only $3^{\circ} \mathrm{C}$ below the mean temperature of injection. The width and thickness of the plume are also satisfactory. Note that the smoothing effect of the regularization is in part counterbalanced by the spatial distribution of the proportion of tap and formation water obtained from hydrogeologic simulations.
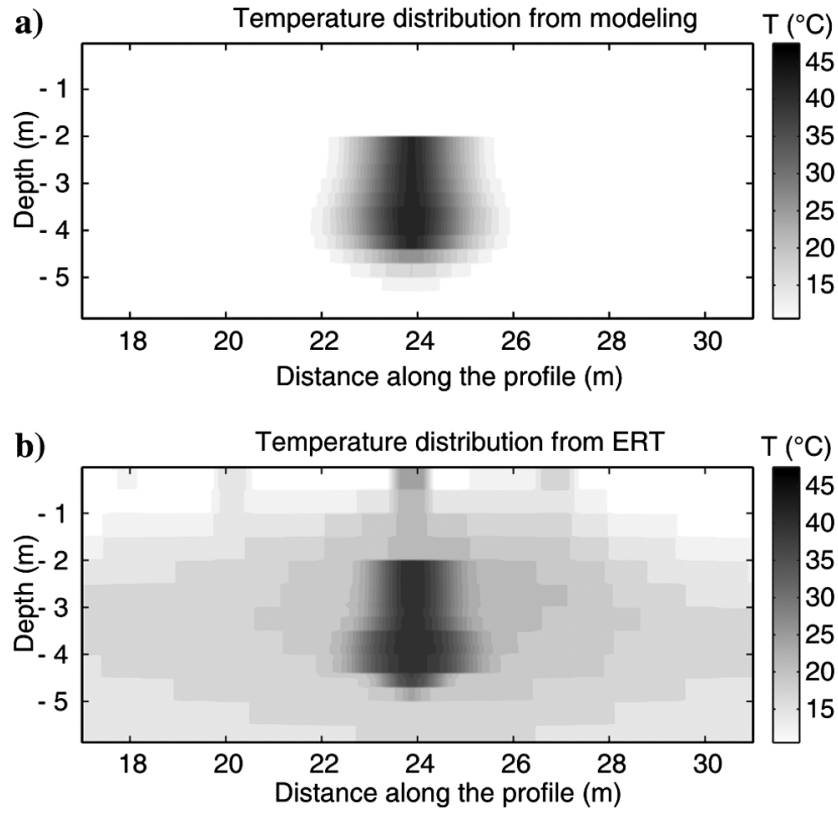

Figure 9. Petrophysical laws enabled to transform resistivity values into temperatures. The plume detected with ERT (b) is in accordance with the plume calculated with a calibrated thermohydrogeologic model (a). 


\section{CONCLUSION}

Electric resistivity tomography appears to be a reliable tool to image injection and storage of heated water and should therefore be further studied to complement thermal response tests. We mapped the extent of a geothermal plume around a borehole, in unfavorable field conditions (varying surface conditions). Changes in resistivity can be interpreted qualitatively to follow the evolution of the plume of heated water in the subsurface and quantitatively to estimate the temperature change. At shallow depths, ERT was able to detect leakage in the bentonite seal and appears as a reliable tool to check in situ geothermal installations, their efficiency and possible heat losses.

Laboratory measurements and site specific petrophysical relationships enabled quantitative interpretation in terms of temperature in the aquifer. Such volumetric information, in contrast with temperature logs, could be of great importance to calibrate thermohydrogeologic models, which often rely on integrated and localized information to calibrate volumetric parameters. In our specific case, the difference in conductivity between formation and injection waters limited the use of inferred temperature directly in the thermohydrogeologic model, even if they appear to be reliable. However, geophysics was used to conceptualize the source term of the thermohydrogeologic model. At present, few techniques address the in situ characterization of low enthalpy geothermal systems and a specific methodology could be developed including ERT and other geophysical methods sensitive to temperature changes.

A limitation to quantify directly hydrogeologic and heat transport parameters with ERT results seems to be the regularization method used to invert the data. It could be interesting to combine forward electric modeling and hydrogeologic modeling in a coupledinversion scheme to avoid the regularization, and thus the smoothing.

A second main disadvantage is the loss of resolution with depth. For deeper geothermal reservoirs, crosshole tomography could be applied to image the temperature distribution in the reservoir. We imaged correctly with surface ERT measurements a $35^{\circ} \mathrm{C}$ temperature change, corresponding to a decrease of $17 \%$ in bulk electric resistivity, using an electrode spacing $a$ of $0.75 \mathrm{~m}$, a 2.5 -m-thick, 3-m-width, and 3-m deep hot water plume. We can generalize these features using nondimensional numbers linked to the electrode spacing $a$ : thickness of $3.33 a$, width and depth of $4 a$. These values can serve as guidelines for further studies and application to deeper reservoirs.

The road ahead is to perform a more quantitative integration of our geophysical data and results in the thermohydrogeologic modeling, if modeling is performed, and to refine the geophysical imaging, if imaging is needed. Our approach should, in time, contribute to the development of in situ techniques to characterize groundwater and porous matrix properties governing heat transfer in the subsurface and to monitor shallow geothermal resources exploitation.

\section{ACKNOWLEDGMENTS}

We would like to thank the Fund for Scientific Research for supporting Thomas Hermans (French Community) as an aspirant and Alexander Vandenbohede (Flanders) as a postdoctoral researcher. We also thank the "Bourse Pisart" of Liege University for giving funds for the internship of Thomas Hermans in Ghent University. We would like to thank deeply the editor Vladimir Grechka and the associate editor for motivating us in improving the manuscript since its first version. We thank A. Revil, L.R. Bentley, and an anonymous reviewer for their constructive remarks leading to a greatly improved manuscript.

\section{REFERENCES}

Allen, A., and D. Milenic, 2003, Low-enthalpy geothermal energy resources from groundwater in fluvioglacial gravels of buried valleys: Applied Energy, 74, 9-19, doi: 10.1016/S0306-2619(02)00126-5.

Alumbaugh, D. L., and G. A. Newman, 2000, Image apraisal for 2-D and 3-D electromagnetic inversion: Geophysics, 65, 1455-1467, doi: 10.1190/1.1444834.

Anderson, M. P., 2005, Heat as a ground water tracer: Ground Water, 43, 951-968, doi: 10.1111/gwat.2005.43.issue-6.

Arango-Galván, C., R. M. Prol-Ledesma, E. L. Flores-Márquez, C. Canet, and R. E. Villanueva Estrada, 2011, Shallow submarine and subaerial, low-enthalpy hydrothermal manifestations on Punta Banda, Baja California, Mexico: Geophysical and geochemical characterization: Geothermics, 40, 102-111, doi: 10.1016/j.geothermics.2011.03.002.

Archie, G. E., 1942, The electrical resistivity $\log$ as an aid in determining some reservoir characteristics: Association for Computing Machinery, Transactions on Mathematical Software, 146, 54-62.

Aster, R. C., B. Borchers, and C. Thurber, 2005, Parameter estimation and inverse problems: Elsevier Academic Press.

Barker, R., and J. Moore, 1998, The application of time-lapse electrical tomography in groundwater studies: The Leading Edge, 17, 1454-1458, doi: 10.1190/1.1437878.

Benderitter, Y., and J. Tabbagh, 1982, Heat storage in a shallow confined aquifer: Geophysical tests to detect the resulting anomaly and its evolution with time: Journal of Hydrology, 56, 85-98, doi: 10.1016/0022-1694(82) 90058-0.

Bentley, L. R., and M. Gharibi, 2004, Two- and three-dimensional electrical resistivity imaging at a heterogeneous remediation site: Geophysics, 69, 674-680, doi: 10.1190/1.1759453.

Bolève, A., A. Crespy, A. Revil, F. Janod, and J. L. Mattiuzzo, 2007, Streaming potentials of granular media: Influence of the Duhkin and Reynolds numbers: Journal of Geophysical Research, 112, B08204, doi: 10.1029/ 2006JB004673.

Bowling, J. C., D. L. Harry, A. B. Rodriguez, and C. Zheng, 2007, Integrated geophysical and geological investigation of a heterogeneous fluvial aquifer in Columbus, Mississippi: Journal of Applied Geophysics, 62, 58-73, doi: 10.1016/j.jappgeo.2006.08.003.

Bruno, P. P. G., V. Paoletti, M. Grimaldi, and A. Rapolla, 2000, Geophysical exploration for geothermal low enthalpy resources in Lipari Island, Italy: Journal of Volcanology and Geothermal Research, 98, 173-188, doi: 10.1016/S0377-0273(99)00183-3.

Busby, J., M. Lewis, H. Reeves, and R. Lawley, 2009, Initial geological considerations before installing ground source heat pump systems: Quarterly Journal of Engineering Geology and Hydrogeology, 42, 295-306.

Buscheck, T. A., C. Doughty, and C. F. Tsang, 1983, Prediction and analysis of a field experiment on a multilayered aquifer thermal energy storage system with strong buoyancy flow: Water Resources Research, 19, 1307-1315, doi: 10.1029/WR019i005p01307.

Butler, J. J., 1998, The design, performance, and analysis of slug tests: Lewis Publishers.

Dahlin, T., and B. Zhou, 2004, A numerical comparison of 2D resistivity imaging with ten electrode arrays: Geophysical Prospecting, 52, 379-398, doi: 10.1111/gpr.2004.52.issue-5.

deGroot-Hedlin, C., and S. Constable, 1990, Occam's inversion to generate smooth, two dimensional models from magnetotelluric data: Geophysics, 55, 1613-1624, doi: 10.1190/1.1442813.

Garg, S. K., J. W. Pritchett, P. E. Wannamaker, and J. Combs, 2007, Characterization of geothermal reservoirs with electrical surveys: Beowave geothermal field: Geothermics, 36, 487-517, doi: 10.1016/ j.geothermics.2007.07.005.

Harbaugh, A. W., E. R. Banta, M. C. Hill, and M. G. McDonald, 2000, MODFLOW-2000, the U.S. Geological Survey modular ground-water model: User guide to modularization concepts and the ground-water process, USGS Open-File Rep, 00-92.

Hayashi, M., 2004, Temperature-electrical conductivity relation of water for environmental monitoring and geophysical data inversion: Environmental Monitoring and Assessment, 96, 119-128, doi: 10.1023/B:EMAS .0000031719 .83065 .68 .

Hayley, K., L. R. Bentley, M. Gharibi, and M. Nightingale, 2007, Low temperature dependence of electrical resistivity: Implications for near surface geophysical monitoring: Geophysical Research Letters, 34, L18402, doi: 10.1029/2007GL031124. 
Hayley, K., L. R. Bentley, and A. Pidlisecky, 2010, Compensating for temperature variations in time-lapse electrical resistivity difference imaging: Geophysics, 75, no. 4, WA51-WA59, doi: 10.1190/1.3478208.

Hyder, Z., J. J. Butler, C. D. McElwee, and W. Liu, 1994, Slug tests in partially penetrating wells: Water Resources Research, 30, 2945-2957, doi: 10.1029/94WR01670.

Jardani, A., A. Revil, W. Barrash, A. Crespy, E. Rizzo, S. Straface, M. Cardiff, B. Malama, C. Miller, and T. Johnson, 2009, Reconstruction of the water table from self-potential data: A Bayesian approach: Ground Water, 47, 213-227, doi: 10.1111/gwat.2009.47.issue-2.

Kaipio, J. P., V. Kolehmainen, M. Vauhkonen, and E. Somersalo, 1999, Inverse problems with structural prior information: Inverse Problems, 15, 713-729, doi: 10.1088/0266-5611/15/3/306.

Keller, G. V., and F. C. Frischknecht, 1966, Electrical methods in geophysical prospecting: Oxford.

Kemna, A., 2000, Tomographic inversion of complex resistivity - Theory and application: Ph.D. thesis, Ruhr-University of Bochum.

Kemna, A., F. Nguyen, and S. Gossen, 2007, On linear model uncertainty computation in electrical imaging: SIAM Conference on mathematical and computational issues in the Geosciences, 82.

Kemna, A., J. Vanderborght, B. Kulessa, and H. Vereecken, 2002, Imaging and characterization of subsurface solute transport using electrical resistivity tomography (ERT) and equivalent transport models: Journal of Hydrology, 267, 125-146, doi: 10.1016/S0022-1694(02)00145-2.

Krautblatter, M., S. Verleysdonk, A. Flores-Orozco, and A. Kemna, 2010, Temperature-calibrated imaging of seasonal changes in permafrost rock walls by quantitative electrical resistivity tomography (Zugspitze, German/Austrian Alps): Journal of Geophysical Research, 115, F02003, doi: 10.1029/2008JF001209.

LaBrecque, D. J., M. Miletto, W. Daily, A. Ramirez, and E. Owen, 1996a, The effects of noise on Occam's inversion of resistivity tomography data: Geophysics, 61, 538-548, doi: 10.1190/1.1443980.

LaBrecque, D. J., A. L. Ramirez, W. D. Daily, A. M. Binley, and S. A. Schima, 1996b, ERT monitoring of environmental remediation processes: Measurement Science and Technology, 7, 375-383, doi: 10.1088/ 0957-0233/7/3/019.

LaBrecque, D. J., and X. Yang, 2000, Difference inversion of ERT data: A fast inversion method for 3-D in-situ monitoring: Proceedings SAGEEP, 723-732.

Langevin, C. D., A. M. Dausman, and M. C. Sukop, 2010, Solute and heat transport model of the Henry and Hilleke laboratory experiment: Ground Water, 48, 757-770, doi: 10.1111/j.1745-6584.2009.00596.x.

Langevin, C. D., D. T. Thorne, A. M. Dausman, M. C. Sukop, and W. Guo, 2007, SEAWAT Version 4: A computer program for simulation of multi-species solute and heat transport, U.S. Geolological Survey Technical Methods, Book 6, chap. A22.

Lebbe, L., M. Mahouden, and W. De Breuck, 1992, Execution of a triple pumping test and interpretation by an inverse numerical model: Applied Hydrogeology, 4, 20-34.

Legaz, A., J. Vandenmeulebrouck, A. Revil, A. Kemna, A. W. Hurst, R. Reeves, and R. Papasin, 2009, A case study of resistivity and selfpotential signatures of hydrothermal instabilities, Inferno Crater Lake, Waimangu, New Zealand: Geophysical Research Letters, 36, L12306, doi: 10.1029/2009GL037573.

Leroy, P., A. Revil, A. Kemna, P. Cosenza, and A. Ghorbani, 2008, Complex conductivity of water-saturated packs of glass beads: Journal of Colloid and Interface Science, 321, 103-117, doi: 10.1016/j.jcis.2007.12.031.

Lund, J. W., 2010, Direct utilization of geothermal energy: Energiespectrum, 3, 1443-1471, doi: 10.3390/en3081443.

Lund, J. W., D. H. Freeston, and T. L. Boyd, 2005, Direct application of geothermal energy: 2005 worldwide review: Geothermics, 34, 691-727, doi: 10.1016/j.geothermics.2005.09.003.

Ma, R., A. McBratney, B. Whelan, B. Minasny, and M. Short, 2011, Comparing temperature correction models for soil electrical conductivity measurement: Precision Agriculture, 12, 55-66.

Miller, C. R., P. S. Routh, T. R. Brosten, and J. P. McNamara, 2008 , Application of time-lapse ERT imaging to watershed characterization: Geophysics, 73, no. 3, G7-G17, doi: 10.1190/1.2907156.

Molson, J. W., E. O. Frind, and C. D. Palmer, 1992, Thermal energy storage in an unconfined aquifer: 2 . Model development, validation, and application: Water Resources Research, 28, 2857-2867, doi: 10.1029/ 92WR01472

Nguyen, F., A. Kemna, A. Antonsson, P. Engesgaard, O. Kuras, R. Ogilvy, J. Gisbert, S. Jorreto, and A. Pulido-Bosch, 2009, Characterization of seawater intrusion using 2D electrical imaging: Near Surface Geophysics, 7, 377-390.

Parasnis, D. S., 1988, Reciprocity theorems in geoelectric and geoelectromanetic work: Geoexploration; International Journal of Mining and Technical Geophysics and Related Subjects, 25, 177-198, doi 10.1016/0016-7142(88)90014-2.
Pérez Flores, M. A., and E. Gomez Trevino, 1997, Dipole-dipole resistivity imaging of the Ahuachapan-Chipilapa geothermal field, El Salvador: Geothermics, 26, 657-680, doi: 10.1016/S0375-6505(97)00015-1.

Ptak, T., M. Piepenbrink, and E. Martac, 2004, Tracer tests for the investigation of heterogeneous porous media and stochastic modelling of flow and transport - A review of some recent developments: Journal of Hydrology, 294, 122-163, doi: 10.1016/j.jhydrol.2004.01.020.

Ramirez, A., W. Daily, D. LaBrecque, E. Owen, and D. Chesnut, 1993, Monitoring an underground steam injection process using electrical resistance tomography: Water Resources Research, 29, 73-87, doi: 10.1029/ 92WR01608.

Revil, A., L. M. Cathles, S. Losh, and J. A. Nunn, 1998, Electrical conductivity in shaly sands with geophysical applications: Journal of Geophysical Research, 103, 23925-23936, doi: 10.1029/98JB02125.

Revil, A., A. Finizola, T. Ricci, E. Delcher, A. Peltier, S. Barde-Cabusson, G. Avard, T. Bailly, L. Bennati, S. Byrdina, J. Colonge, F. Di Ganga, G. Douillet, M. Lupi, J. Letort, and E. Tsang Hin Sun, 2011, Hydrogeology of Stromboli volcano, Aeolian Islands (Italy) from the interpretation of resistivity tomograms, self-potential, soil temperature and soil $\mathrm{CO}_{2}$ concentration measurements: Geophysical Journal International, 186, 1078-1094, doi: 10.1111/j.1365-246X.2011.05112.x.

Revil, A., T. C. Johnson, and A. Finizola, 2010, Three-dimensional resistivity tomography of Vulcan's Forge, Vulcano Island, southern Italy: Geophysical Research Letters, 37, L15308, doi: 10.1029/ 2010GL043983.

Revil, A., and N. Linde, 2006, Chemico-electrochemical coupling in microporous media: Journal of Colloid and Interface Science, 302, 682-694, doi: $10.1016 /$ j.jcis.2006.06.051.

Revil, A., H. Schwaeger, L. M. Cathles, and P. D. Manhardt, 1999, Streaming potential in porous media 2 . Theory and application to geothermal systems: Journal of Geophysical Research, 104, 20033-20048, doi: 10.1029/1999JB900090.

Singha, K., and S. M. Gorelick, 2006, Effects of spatially variable resolution on field-scale estimates of tracer concentration from electrical inversions using Archie's law: Geophysics, 71, no. 3, G83-G91, doi: 10.1190/ 1.2194900

Singha, K., L. Li, F. D. Day-Lewis, and A. B. Regberg, 2011, Quantifying solute transport processes: Are chemically "conservative" tracers electrically conservative?: Geophysics, 76, no. 1, F53-F63, doi: 10.1190/ 1.3511356.

Slater, L., A. M. Binley, W. Daily, and R. Johnson, 2000, Cross-hole electrical imaging of a controlled saline tracer injection: Journal of applied geophysics, 44, 85-102, doi: 10.1016/S0926-9851(00)00002-1.

Suzuki, S., 1960, Percolation measurements based on heat flow through soil with special reference to paddy fields: Journal of Geophysical Research, 65, 2883-2885, doi: 10.1029/JZ065i009p02883.

Tikhonov, A. N., and V. A. Arsenin, 1977, Solution of ill-posed problems: Winston \& Sons.

Vandenbohede, A., T. Hermans, F. Nguyen, and L. Lebbe, 2011, Shallow heat injection and storage experiment: Heat transport simulation and sensitivity analysis: Journal of Hydrology, 409, 262-272, doi: 10.1016/ j.jhydrol.2011.08.024.

Vandenbohede, A., and L. Lebbe, 2002, 3D density dependent numerical model of a tracer test performed in the Belgian coastal plain: Proceeding of the First Geologica Belgica International Meeting, Aardkundige Mededelingen, 12, 223-226.

Vandenbohede, A., and L. Lebbe, 2003, Combined interpretation of pumping and tracer tests: Theoritical considerations and illustration with a field test: Journal of Hydrology, 277, 134-149, doi: 10.1016/S0022-1694(03) 00090-8.

Vandenbohede, A., and L. Lebbe, 2006, Double forced gradient tracer test: Performance and interpretation of a field test using a new solute transport model: Journal of Hydrology, 317, 155-170, doi: 10.1016/j.jhydrol.2005 .05 .015 .

Vandenbohede, A., A. Louwyck, and L. Lebbe, 2009, Conservative solute versus heat transport in porous media during push-pull tests: Transport in Porous Media, 76, 265-287, doi: 10.1007/s11242-008-9246-4.

Vanderborght, J., A. Kemna, H. Hardelauf, and H. Vereecken, 2005, Potential of electrical resistivity tomography to infer aquifer transport characteristics from tracer studies: A synthetic case study: Water Resources Research, 41, W06013, doi: 10.1029/2004WR003774.

Waxman, M. H., and L. J. M. Smits, 1968, Electrical conductivities in oilbearing shaly sands: Society of Petroleum Engineers Journal, 8, 107-122, doi: $10.2118 / 1863-A$

Zheng, C., and P. P. Wang, 1999, MT3DMS, a modular three-dimensional multispecies model for simulation of advection, dispersion and chemical reactions of contaminants in groundwater systems: Documentation and user's guide, U.S. Army Engineer Research and Development Center Contract Report SERDP-99-1. 